\title{
Impact of Perceived Social Support, Resilience, and Subjective Well-Being on Psychological Distress among University Students: Does Gender Make a Difference?
}

\author{
Ayesha Saddique, Seng Choi Chong, Aiman Almas, Maryam Anser, \\ Shumaila Munir
}

To Link this Article: http://dx.doi.org/10.6007/IJARBSS/v11-i2/8331

DOI:10.6007/IJARBSS/v11-i2/8331

Received: 14 December 2020, Revised: 12 January 2021, Accepted: 19 January 2021

Published Online: 05 February 2021

In-Text Citation: (Saddique et al., 2021)

To Cite this Article: Saddique, A., Chong, S. C., Almas, A., Anser, M., \& Munir, S. (2021). Impact of Perceived Social Support, Resilience, and Subjective Well-Being on Psychological Distress among University Students: Does Gender Make a Difference. International Journal of Academic Research in Business and Social Sciences, 11(2), 27-41.

\section{Copyright: (c) 2021 The Author(s)}

Published by Human Resource Management Academic Research Society (www.hrmars.com) This article is published under the Creative Commons Attribution (CC BY 4.0) license. Anyone may reproduce, distribute, translate and create derivative works of this article (for both commercial and non-commercial purposes), subject to full attribution to the original publication and authors. The full terms of this license may be seen at: http://creativecommons.org/licences/by/4.0/legalcode

Vol. 11, No. 2, 2021, Pg. 27 - 41

Full Terms \& Conditions of access and use can be found at http://hrmars.com/index.php/pages/detail/publication-ethics 


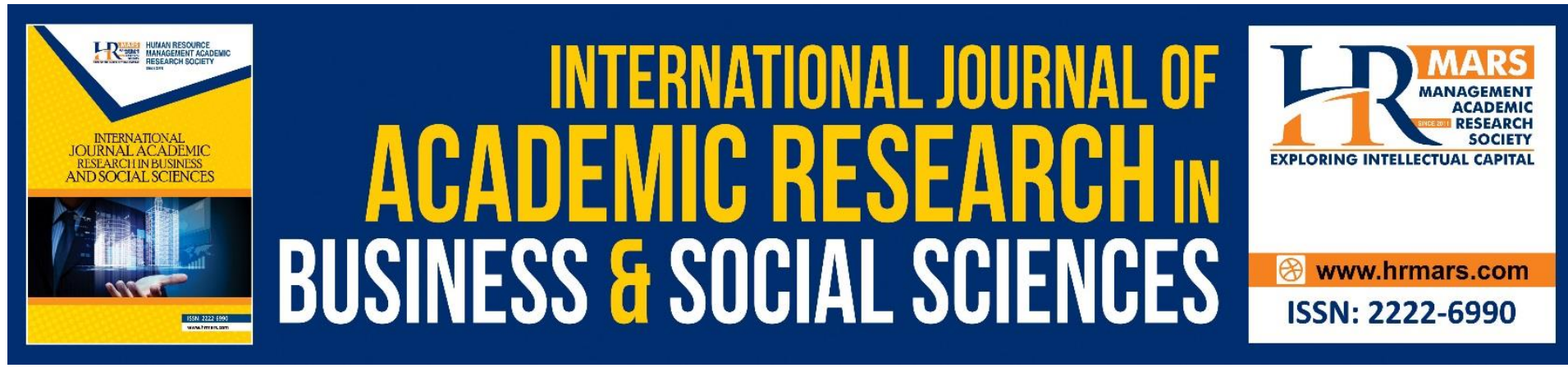

\title{
Impact of Perceived Social Support, Resilience, and Subjective Well-Being on Psychological Distress among University Students: Does Gender Make a Difference?
}

\author{
Ayesha Saddique, Seng Choi Chong, Aiman Almas, Maryam \\ Anser, Shumaila Munir \\ University Putra Malaysia \\ Email: sengchoi@upm.edu.my
}

\begin{abstract}
The academic literature on educational psychology has provided extensive insights into the determinants of psychological distress. However, few empirical studies have explored whether and how three core components of psychological distress (i.e., perceived social support, resilience, and subjective well-being) affect students' mental health. Developing the concept of psychological distress from social support theory perspectives, this research explores the predictors of psychological distress among educational institutions of Pakistan. The purpose of the study is to delve into the influencing factors of psychological distress namely, perceived social support, subjective well-being, and resilience. Additionally, gender difference has created immense ambition, enthusiasm drivers of psychological distress. Methodologically, this research is developing an approach of quantitative method. Accordingly, this research contributes to use a survey method to address the psychological distress among university students. Data were obtained from 389 university students. Additionally, partial least square structural equation modeling (PLS-SEM 3.2.9) software was tested to examining the hypothesis and effects of predictors. In the means of testing our hypothesis and thus quantifying it, the results have led us to confirm an overall positive effect of perceived social support, subjective well-being, and resilience on psychological distress. Additionally, this research carry-out the context of gender difference acts as an emerging concept in the psychological distress context. Based on the findings, this research provides females with a higher influence on psychological distress than male. Further, the implications for policymakers to promote mental health care mechanism for facilitating new health care atmosphere and getting the foremost advantage of mental satisfaction and academic performance.
\end{abstract}

Keywords: Psychological Distress, Perceived Social Support, Subjective Well-Being, Resilience, Gender Differences 


\section{Introduction}

Over the past decades, the notion of psychological distress gaining traction in educational psychology literature, including cognitive and behavioral perspectives (Kang et al., 2020). Nowadays, fast-spreading psychological distress becoming a nightmare for mental health, and emerging with student's mental disorders (Qiu et al., 2020). The University atmosphere has started losing hold of the potential mental health care mechanism and facing mammoth challenges of containing psychological pressure and new potential stressors (e.g., academic pressures and relational challenges). Moreover, a relatively high yield of mental diseases is creating a loss-loss situation for mental health mechanisms. In developing nations (notably Pakistan), psychological distress has been recognized with its praise for the emotional suffering problems and plaudits for spreading symptoms of depression and anxiety among university students (Every-Palmer et al., 2020). As a result, a new turning point is an insight that often exists common somatic complaints, a wider range of chronic situations, and medically unfitness syndromes. With higher unexplained syndrome measures being gradually lifted university student's mental health conditions very behind (Shechter et al., 2020). Despite the prevailing circumstances, psychological distress has grown very rapidly among university students in Pakistan, and it looks difficult for maintaining the balance between mental health disorders and psychological challenges (Hasan \& Bao, 2020). However, the role of perceived social supports is dominant as visionary and solution maker. Progressively, perceived social supports begun to provide support, not only for solving psychological issues even provides the core mental health care (Lin, Broström, Griffiths, \& Pakpour, 2020). Particularly, recent calls suggested that perceived social supports, subjective well-being, and resilience become a foreseeable choice for gaining mental satisfaction under increasing mental disorder problems. Recently, universities are paying great encouragement towards the concept of psychological distress, to preserve the student's mental health care tasks.

Despite the growing scholars' attention toward the concept of perceived social support e.g., (Zhou, 2020), and its relationship with mental health care e.g., (Hamza, Ewing, Heath, \& Goldstein, 2020), how it influences psychological distress still unclear (Holingue et al., 2020), some past literature proposed positive relationship of perceived social support in the shape of emotional support (Satici, Gocet-Tekin, Deniz, Satici, \& Addiction, 2020), tangible support (Serafini et al., 2020), informational support (Petzold et al., 2020), companionship support (Every-Palmer et al., 2020). Further, the role of perceived social support sheds light on unobserved issues regarding mental health and its related behaviors such as schizophrenia, bipolar disorder, and anxiety disorders (Nishi et al., 2020). Unfortunately, over the last decade, the role of perceived social support about mental health and its related behaviors remains largely absent. Also, the concept of subjective well-being has been studied in relationship with various development psychology literature such as spirituality, medical illness perspectives, academic performance and achievements (Shechter et al., 2020), institutional pressure (Latif et al., 2020) hope and optimism (Hao et al., 2020). However, how subjective well-being influences psychological distress is still debatable. Considering the above inconsistent arguments, this research is aimed at addressing these research gaps by demonstrates the concept of perceived social support, subjective well-being, resilience, and its effect on psychological distress which were rarely taken into the consideration in previous research (Collie et al., 2020).

The present study attempts to fill these research gaps by investigating the role of perceived social support, subjective well-being, and resilience on psychological distress, 
through investigating the gender difference as an emerging concept. Hence, this research aims to seek answers to the following research questions:

- Does perceived social support influence psychological distress?

- Does subjective well-being influence psychological distress?

- Does resilience influence psychological distress?

- Does gender influence psychological distress?

For this purpose, this study has proven the usefulness of social support theory (SST) perspectives, present research shed light on the impacts of perceived social support, subjective well-being, and resilience on psychological distress, in the context of Pakistani public and private universities. Social support theory prolonged the debate on psychological distress and described that perceived social support, subjective well-being, and resilience has greatly influenced psychological distress among university students. According to social support theory (SST), a high level of social support mechanism more likely to increase happiness and satisfaction and decrease mental health problems, whereas a low level of social support more likely to increase psychological distress including depressive symptoms (Ben-Tzur, Zanbar, \& Kaniasty, 2020). Social support has directly and indirectly impacted mental health and its other indicators. As a direct impact, social support tends to decrease mental health problems and engage in happiness and satisfaction. As an indirect impact, social support may act as a problem solver between mental health problems and psychological distress. Also, the present study aims to address the role of gender differences in psychological distress. In previous studies, women are considered more likely depressed and emotional than males (Tsuchiya, Adachi, Kumagai, Kondo, \& Kimata, 2020). The stress reactivity model has proposed that gender differences are a key enabler that could best describe the attributes of stress and anxiety among different genders (Chen, 2020). According to the stress reactivity model, women need to adopt social assistance, to revealing stress and preventing anxiety. Some researcher has argued that man has broader social networking than man (Moore \& Lucas, 2020). Despite these facts, the role of gender differences is found unclear in psychological distress literature. Hence, therefore, the present study sheds light on the role of gender differences in the psychological distress context. The primary objective of this research is to reveal the role of gender difference on psychological distress among university students whether females' students tend to report a higher propensity of psychological distress than males. Further, the investigation of perceived social support, subjective well-being, and resilience on psychological distress show the disparity of stress and anxiety among females and males. The next section of this study demonstrated a literature review and hypothesis development of every variable. Subsequently, further sections describe the methodology and data analysis section. The final section of this research carries out the discussion, limitation, and conclusions section.

\section{Literature Review and Hypothesis Development Perceived Social Support and Psychological Distress}

The literature on perceived social support and psychological distress validated that perceived social support is a valuable tool that motivates and encourages better mental health and explores possible ways for avoiding psychological distress. Over the past decade, it is argued that a higher propensity for social support is reported as being associated with lower levels of depression, anxiety, and stress (Every-Palmer et al., 2020). Further, university students who acknowledged higher levels of perceived social support may result in increased self-efficacy and sleep quality which can reduce anxiety, depression, and stress (Shechter et al., 2020). 
Hence, however, higher levels of perceived social support may associate to report better effects on social isolation and social distancing measures (Hasan \& Bao, 2020). According to social support theory (SST) perspectives, perceived social support can contribute their effort, knowledge, and experience to improve mental health regardless of the presence of stressors, while perceived social support possess university students to build their mental abilities stronger, to achieve academic success. Numerous pieces of literature have suggested that demographic variables have a significant impact on psychological distress. For example, females students have been found more likely emotional and more health-related concerns than male students (Lin et al., 2020). Moreover, finding generally stated that gender is an important factor to consider when examining university student's mental health (Zhou, 2020). It is argued that low perceived social support students tend to face more likely mental problems, including psychological distress (Holingue et al., 2020). However, perceived social support is the combination of internal and external social support e.g., family support, friends support, and other supports. This reflected that involvement of overall social support is highly reduced mental disorder and stressors. Based on the above argument, the following hypothesis has been developed.

H1. Perceived social support influences psychological distress positively.

\section{Subjective Well-being and Psychological Distress}

The concept of subjective well-being growing long-term traction in the field of psychology and socioeconomic or sociology (Anderson, Fowers, \& Medicine, 2020), demonstrated as individuals' evaluation of their own subjective experiences of life (Shechter et al., 2020). Subjective well-being is recognized as a multi-dimensional concept, in which practices are covering subjective, social, physical, psychological, and health-related behaviors. A recent call suggested that subjective well-being implies a positive influence on mental health and it is fostering happiness and satisfaction. However, it is argued that positive emotions individual has tended to be more strong subjective well-being (Hao et al., 2020). Additionally, a high propensity for subjective well-being decreases the chance of psychological problems. According to (Collie et al., 2020), six-core dimensions of subjective well-being are drawing theoretical guidance from developmental psychology, clinical psychology, and literature on mental health. According to the social support theory (SST) perspective, subjective well-being is the key enabler that fostering better mental health outcomes, but it is important to understand their right behaviors and actions (Every-Palmer et al., 2020). Subjective well-being is the key motivator that aims at accelerating the students to stable their emotions which can sorted-out their depressive symptoms. Taken together, it is mentioned that the link between subjective well-being influences psychological distress. Drawing the concept of subjective well-being from social support theory (SST), the concept of subjective well-being posited that subjective well-being is basic psychological competence that helps to cope up with psychological distress and fostering happiness and satisfaction.

H2. Subjective well-being influences psychological distress positively.

\section{Resilience and Psychological Distress}

Resilience is recognized as an emerging concept that has explained the behavior of individuals under immense stress and adaptation of necessary actions. Concerning psychological counseling, resilience is considered a more reliable tool for student's counseling practices. Currently, university students are struggling with increasing psychological problems (Nishi et al., 2020). Particularly, recent call suggested that unexplained psychological problem has 
greatly emerged with academic pressures. At the same time, resilience has brought reducing mental health problems by counseling and social support mechanism. In earlier research, resilience plays a vital role associated with motivation, mental health disorder literature, while the resilience effects along with perceived social support and subjective well-being on psychological distress are still unexplored. However, increasing numbers of psychological problems have triggered an alarming situation for mental health. In response, the essence of resilience has greatly assessed, promotes, and endeavors the mechanism to solve psychological problems such as mental illness and psychological distress (Collie et al., 2020). Resilience is considered a strategically essential resource for a student's mental health. Resilience is used to promote knowledge resource management that can influence the mental disorder as well as to foster psychological distress. However, this research is exploring the influential role of resilience on psychological distress among university students. It is commonly known that resilience carries important knowledge resources to foster psychological distress. Resilience is proved as an important predictor because it is considered a prerequisite for psychological actions. Moreover, it is important to understand the perceived social support and resources needed to achieve better mental health while resilience is the key factor that predicted certain behavior to cope-up with psychological distress. According to social support theory (SST) perspectives, resilience formulates psychological strategies that bolster academic performance (Moore \& Lucas, 2020). Moreover, long-term academic successes require stronger resilience to cover and protect the need for a psychological disorder. However, this research supports the notion of resilience facilitation for psychological distress. Based on the above argument, the following hypothesis has been developed.

H3. Resilience influences psychological distress positively.

\section{Research Framework}

The main objective of this study to investigate the positive effects of perceived social support, resilience, and subjective well-being on psychological distress in public and private universities of Pakistan. It further investigates the role of gender differences, influencing the relationship between perceived social support, resilience and subjective well-being, and psychological distress. The research framework and hypothesis are as followed in figure 1.

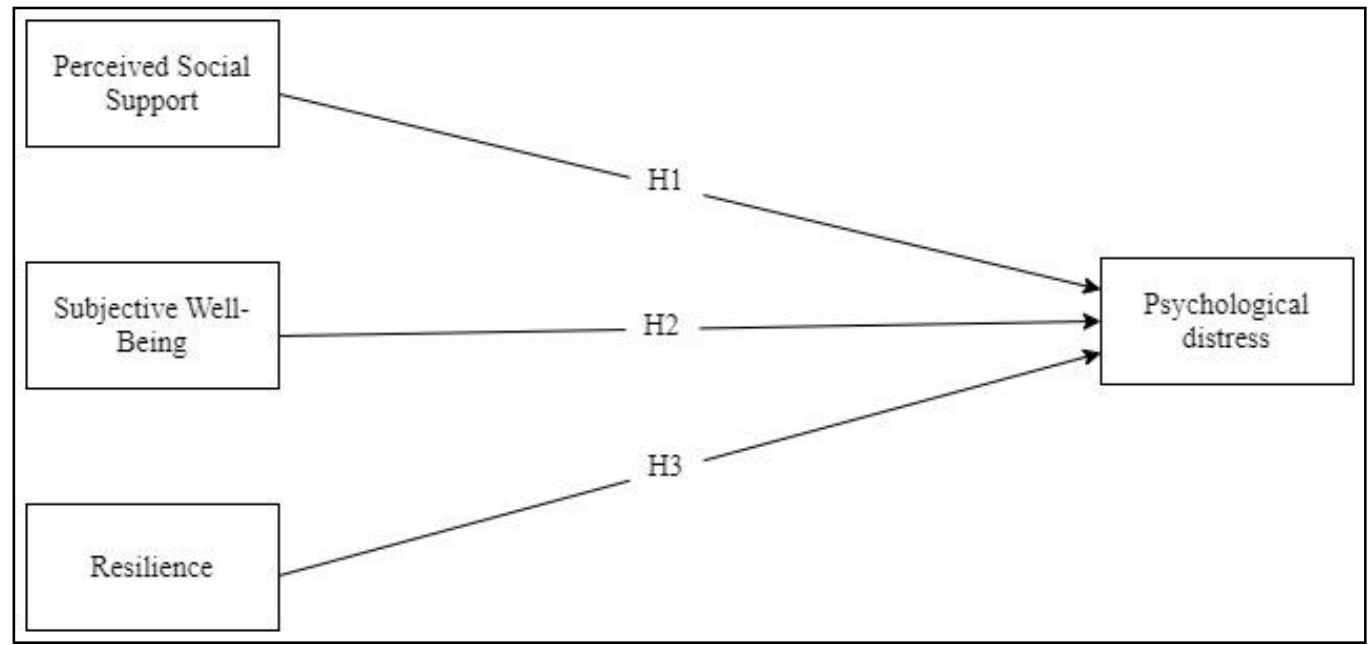

\section{Research Methodology}

The present study is based on quantitative methods with a positivist paradigm in nature. The study population included students from public and private universities in the province of 
Punjab, Pakistan. The selection of the educational sector was designated due to it is having a big impact on the student's psychological distress and health care context. Moreover, the sample of this study was comprised of 13 public and private universities of province Punjab, Pakistan. The selection of Punjab was noteworthy for many reasons. Firstly, Punjab have relatively higher shares in universities ratio as compare to any other province of Pakistan, respectively $27 \%$ shares of public universities and $24 \%$ shares of private universities. Hence, therefore, the majority of higher education institutions (HEIs) and degree awarded institutions (DAls) are clustered in the province of Punjab. Secondly, over the past 40 years, the Punjab literacy rate has increased greatly. It represents a $61 \%$ literacy rate that is considered the highest literacy rate as compared to another province of Pakistan. Moreover, Punjab has the highest Human Development Index out of all of Pakistan's provinces at 0.567. However, target participants were undergraduate and postgraduate university students, belonged to faculties of management, economics, arts, communication, humanities, sciences, information technology, and health sciences, all participants were asked to participate in the survey and respond to the questionnaire.

\section{Research Design}

The present study has been applied to a simple random sampling technique for preserving the respondent's anonymity. For accuracy and evaluation of sample size, the present research applied G*Power 3.1.9.2 software that is the most recognized and reliable software for the examination of statistical test required for sample size. Moreover, G*Power is mostly recommended for the sample size calculation (Cohen, 1992). Based on the calculation of $G^{*}$ Power, the present study required a sample size should $(N=140)$ respondents. According to setting proposed by (Cohen, 1992), $f 2=.15$ (effect size), $\alpha=.05$ (error type one), $\beta=0.20$ (error type two). Meanwhile, 700 questionnaires were distributed, several follow-ups and phone calls were made to get the response. Finally, 438 questionnaires returned-back, out of 49 questionnaires were incomplete and removed. As a result, 389 questionnaires were valid and usable, representing an overall response rate of $55.57 \%$ (389/700). Hence, details of the demographic characteristics of this sample have been presented in Table 1 
Table 1: Demographic Statistics of the Sample Data

\begin{tabular}{lcc}
\hline & Demographic Statistics & \\
& Frequency & $\%$ \\
\hline Gender & & \\
Male & 201 & 51.7 \\
Female & 188 & 48.3 \\
Age & & \\
$<20$ & 301 & 77.3 \\
$>20$ & 88 & 22.6 \\
University & & \\
Public university & 180 & 46.2 \\
Private university & 209 & 53.7 \\
Field of study & & \\
Management \& Economics & 148 & 38.4 \\
Sciences \& IT & 146 & 37.5 \\
Arts, communication \& language & 78 & 20.5 \\
Health sciences & 17 & 4.37 \\
Year of study & & \\
Year 1 & 84 & 21.5 \\
Year 2 & 139 & 35.7 \\
Year 3 & 70 & 17.9 \\
Year 4 & 96 & 24.6 \\
\hline
\end{tabular}

\section{Measurement of Scale}

This research adopts the scales from previous research, which provides greater insights into the validity and reliability of the research findings. Six items of psychological distress were measured by (Glass et al., 2009), Five items of resilience were measured and adopted by (Hartley, 2012), five items of perceived social support were measured and adopted by (Zimet, Powell, Farley, Werkman, \& Berkoff, 1990) and five items of subjective well-being were measured and adopted by (Larsen, Diener, \& Emmons, 1985). A five-point Likert scale is used to assess the response of the target respondent whereas 1 represents "strongly disagree" and 5 representing "strongly agree".

\section{Data Analysis}

The present study has applied the partial least square (PLS-SEM) for investigating the relationship between different hypotheses. However, there are two reasons for selecting PLSSEM as a supporting data analysis section. Firstly, the present study uses a composite variable (Henseler, 2018). Secondly, PLS-SEM can highly recommend for a small sample size (Richter, Cepeda-Carrión, Roldán Salgueiro, \& Ringle, 2016). Thirdly, PLS-SEM observed the relationship between latent variables and their constructs (Ringle \& Sarstedt, 2016). Fourthly, PLS-SEM largely deals with various applications such as correlation structure model, regression analysis, path analysis, confirmatory factor analysis, covariance structure analysis, and second-order factor analysis. Finally, PLS-SEM is well-known and best-recommended software for psychology studies for multivariate analysis. 


\section{Results}

The data analysis section is categorized into two parts, the first part is dealing with measurement model analysis while the second part is dealing with the structural equation model analysis.

\section{Measurement Model Assessment}

This research examined the adequacy of the measurement model by investigating the reliability, discriminant validity, and convergent validity of each construct. Measurement model assessment is evaluated the fit between theory and data (Henseler, 2018). Measurement model assessment examined the relationship between manifest variables (observed items) and latent variables (unobserved items). Moreover, the measurement model examined the reliability and validity of the constructs operationalized in the research model. This evaluation ensures the reliable measures and valid constructs that were used to examine the nature of the relationship in the proposed model. Further, PLS techniques permitted two different types of measurements: reflective and formative measures (Ringle \& Sarstedt, 2016). Measurement model assessment is followed by four criteria's namely, internal consistency, internal reliability, convergent validity, and discriminant validity (Henseler, 2018). Convergent validity displays the validation of each construct in the measurement model. When a measure is highly correlated with different measures of similar constructs then it shows convergent validity. Convergent validity is supported when the average variance extracted is equal and greater than 0.5 for each item factor loadings (outer loading) and above 0.7 (Hair Jr, Sarstedt, Hopkins, \& Kuppelwieser, 2014). As shown in table 4 , reliability was investigating by individual item loadings which represent latent variables $(0.7$ were accepted). Cronbach's alpha was used as examining the reliability index of latent variables. However, composite reliability and average variance extracted were evaluated ( $>0.5$ were accepted). To verify the discriminant validity of each construct, PLS-SEM carried out the measurement properties. Also, the Fornell-larcker criterion highlights the discriminant validity, according to this criterion, whether the square root of AVE of each construct was higher than their correlations with other constructs.

Table 2: Descriptive statistics and T-Test

\begin{tabular}{lccc}
\hline \multicolumn{1}{c}{ Latent Variable } & Gender & Mean (SD) & t-Test (Sig.) \\
\hline Perceived Social Support & Male & $3.89(.82)$ & -1.774 \\
& Female & $4.02(.62)$ & $(.008)$ \\
Psychological distress & Male & $4.04(.78)$ & -2.181 \\
& Female & $4.20(.64)$ & $(.125)$ \\
Resilience & Male & $3.47(.66)$ & -1.624 \\
& Female & $3.57(.56)$ & $(.078)$ \\
Subjective Well-Being & Male & $3.66(.93)$ & -2.480 \\
& Female & $3.86(.69)$ & $(.036)$ \\
\hline
\end{tabular}


Table 3: Discriminant Validity (Fornell \& Larcker and Heterotrait-Monotrait Ratio HTMT)

\begin{tabular}{lcccc}
\hline & $\begin{array}{c}\text { Perceived } \\
\text { Social Support }\end{array}$ & $\begin{array}{c}\text { Psychological } \\
\text { distress }\end{array}$ & Resilience & $\begin{array}{c}\text { Subjective } \\
\text { Well-Being }\end{array}$ \\
\hline $\begin{array}{l}\text { Perceived Social } \\
\text { Support }\end{array}$ & 0.791 & 0.268 & 0.443 & 0.706 \\
Psychological distress & 0.496 & 0.773 & 0.507 & 0.492 \\
Resilience & 0.429 & 0.453 & 0.893 & 0.567 \\
Subjective Well-Being & 0.602 & 0.383 & 0.225 & 0.752 \\
\hline
\end{tabular}

* Diagonal bold value is the square root of AVE.

* Upper values are the HTMT ratio which is $<0.90 /<0.85$

Table 4: Measurement Model (Outer Model)

\begin{tabular}{|c|c|c|c|c|c|c|}
\hline \multicolumn{4}{|c|}{ Items } & \multirow{2}{*}{$\frac{\text { All }}{0.849}$} & \multirow{2}{*}{$\frac{\text { Male }}{0.869}$} & \multirow{2}{*}{$\frac{\text { Female }}{0.808}$} \\
\hline Perceived social support & & Cronbach' & & & & \\
\hline \multirow[t]{7}{*}{ 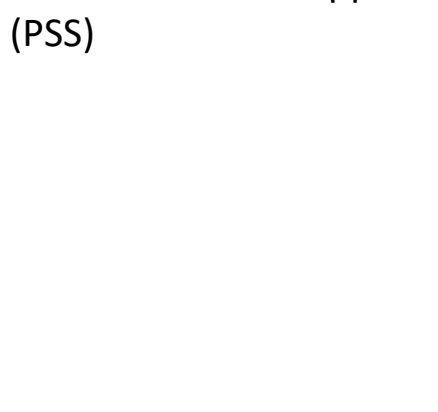 } & & \multicolumn{2}{|c|}{ Composite Reliability } & 0.893 & 0.904 & 0.870 \\
\hline & & $\begin{array}{l}\text { Average } \\
\text { Extracted }\end{array}$ & Variance & 0.626 & 0.655 & 0.580 \\
\hline & PSS1 & & & 0.809 & 0.834 & 0.799 \\
\hline & PSS2 & & & 0.839 & 0.857 & 0.803 \\
\hline & PSS3 & & & 0.833 & 0.838 & 0.818 \\
\hline & PSS4 & & & 0.802 & 0.777 & 0.833 \\
\hline & PSS5 & & & 0.659 & 0.735 & 0.504 \\
\hline \multirow{8}{*}{$\begin{array}{l}\text { Subjective well-being } \\
\text { (SWB) }\end{array}$} & & \multirow{2}{*}{\multicolumn{2}{|c|}{$\begin{array}{l}\text { Cronbach's Alpha } \\
\text { Composite Reliability }\end{array}$}} & 0.810 & 0.824 & 0.787 \\
\hline & & & & 0.866 & 0.870 & 0.854 \\
\hline & & $\begin{array}{l}\text { Average } \\
\text { Extracted }\end{array}$ & Variance & 0.565 & 0.572 & 0.540 \\
\hline & SWB1 & & & 0.790 & 0.792 & 0.763 \\
\hline & SWB2 & & & 0.799 & 0.798 & 0.777 \\
\hline & SWB3 & & & 0.718 & 0.726 & 0.683 \\
\hline & SWB4 & & & 0.742 & 0.703 & 0.789 \\
\hline & SWB5 & & & 0.706 & 0.758 & 0.652 \\
\hline Resilience & & \multirow{2}{*}{\multicolumn{2}{|c|}{$\begin{array}{l}\text { Cronbach's Alpha } \\
\text { Composite Reliability }\end{array}$}} & 0.873 & 0.889 & 0.845 \\
\hline \multirow[t]{7}{*}{ (RES) } & & & & 0.922 & 0.931 & 0.904 \\
\hline & & $\begin{array}{l}\text { Average } \\
\text { Extracted }\end{array}$ & Variance & 0.797 & 0.818 & 0.758 \\
\hline & RES1 & & & Drop & Drop & Drop \\
\hline & RES2 & & & Drop & Drop & Drop \\
\hline & RES3 & & & 0.904 & 0.919 & 0.866 \\
\hline & RES4 & & & 0.893 & 0.899 & 0.893 \\
\hline & RES5 & & & 0.881 & 0.896 & 0.851 \\
\hline Psychological distress & & \multirow{2}{*}{\multicolumn{2}{|c|}{$\begin{array}{l}\text { Cronbach's Alpha } \\
\text { Composite Reliability }\end{array}$}} & 0.865 & 0.894 & 0.805 \\
\hline \multirow[t]{5}{*}{$(P D)$} & & & & 0.899 & 0.918 & 0.860 \\
\hline & & $\begin{array}{l}\text { Average } \\
\text { Extracted }\end{array}$ & Variance & 0.597 & 0.653 & 0.508 \\
\hline & PD1 & & & 0.820 & 0.847 & 0.755 \\
\hline & PD2 & & & 0.806 & 0.849 & 0.718 \\
\hline & PD3 & & & 0.816 & 0.831 & 0.788 \\
\hline
\end{tabular}




\begin{tabular}{llll} 
PD4 & 0.741 & 0.769 & 0.695 \\
PD5 & 0.760 & 0.794 & 0.700 \\
PD6 & 0.686 & 0.752 & 0.606 \\
\hline
\end{tabular}

\section{Structural Model Assessment}

The structural equation model is measured by applying PLS-SEM bootstrapping for the construction of significant correlations. Bootstrapping has been applied on 5000 resample of each case (Hair Jr et al., 2014). The results are shown in Table 5 reflected the relationship between exogenous variables and endogenous variables of PLS-SEM analysis. This study has emphasized the role of gender difference in the research framework. However, results of structural equation model revealed that perceived social support have positive relationship with psychological distress in both gender: male $(\beta=0.227, t=2.121, p$-value $=0.034)$, female $(\beta=0.345, t=5.108, p$-value $=0.000)$. Therefore, the first hypothesis has fulfilled a significant threshold and is strongly accepted. In addition, second hypothesis described that subjective well-being has positive and significant relationship with psychological distress in female $(\beta=$ $0.260, t=3.577, p$-value $=0.000$ ) However, surprisingly, subjective well-being has insignificant relationship with psychological distress in male $(\beta=0.123, t=0.973, p$-value $=0.331)$. However, the second hypothesis has fulfilled the significant criteria and strongly accepted in females, while the second hypothesis is rejected in males. Lastly, third hypothesis demonstrated that resilience has positive and significant relationship with psychological distress in both gender: male $(\beta=0.350, t=5.246, p=0.000)$, female $(\beta=0.224, t=3.78, p=$ 0.000 ) representing that third hypothesis is strongly accepted.

Table 5: Hypothesis Testing.

\begin{tabular}{llccccc}
\hline \multicolumn{1}{c}{ Hypothesis (Male) } & $\beta$ & SD & $\begin{array}{c}T- \\
\text { value }\end{array}$ & $\begin{array}{c}\text { Values } \\
\text { Values }\end{array}$ & (Sig.) \\
\hline H1 & Perceived Social Support -> Psychological distress & 0.227 & 0.107 & 2.121 & 0.034 & + \\
H2 & Subjective Well-Being -> Psychological distress & 0.123 & 0.126 & 0.973 & 0.331 & - \\
H3 & Resilience -> Psychological distress & 0.350 & 0.067 & 5.246 & 0.000 & + \\
& $\quad$ & & & & & \\
$\quad$ Hypothesis (Female) & & & & & \\
H1 & Perceived Social Support -> Psychological distress & 0.345 & 0.067 & 5.108 & 0.000 & + \\
H2 & Subjective Well-Being -> Psychological distress & 0.260 & 0.073 & 3.577 & 0.000 & + \\
H3 & Resilience -> Psychological distress & 0.224 & 0.059 & 3.78 & 0.000 & + \\
\hline
\end{tabular}

* + signs show the significant or supported relationship of the variables.

* - signs show the insignificant or not supported relationship of the variables. 

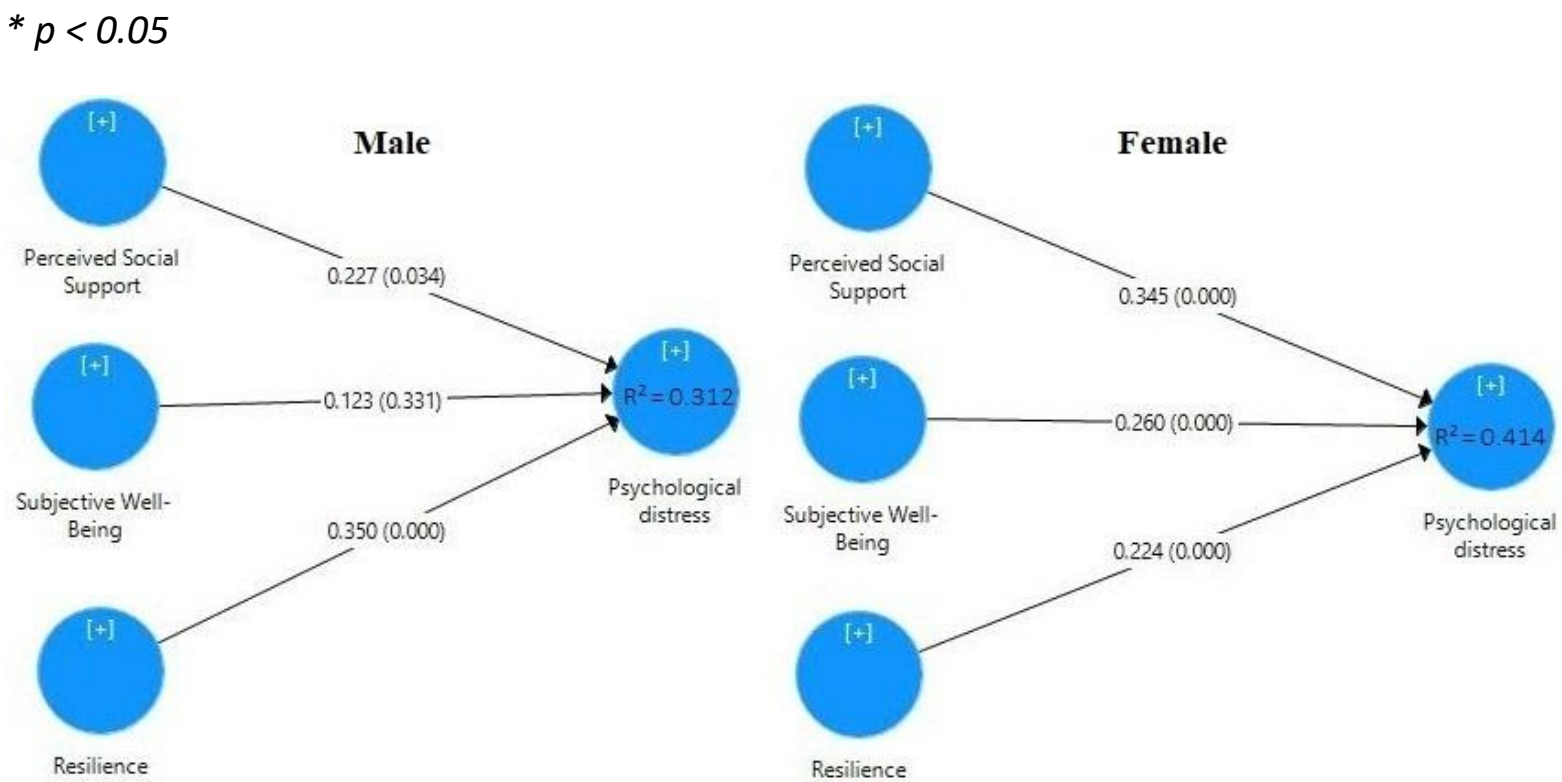

Figure 2: Comparison of Gender

\section{Discussion}

Drawing on social support theory perspectives, the present study aims to address three important research questions: Does perceive social support influence psychological distress? Does subjective well-being influence psychological distress? Does resilience influence psychological distress? However, the first objective indicates the direct relationship of perceived social support, subjective well-being, and resilience on psychological distress, concerning these direct effects represented by the $\mathrm{H} 1, \mathrm{H} 2$, and $\mathrm{H} 3$ hypotheses. Current findings suggested that $\mathrm{H} 1, \mathrm{H} 2$, and $\mathrm{H} 3$ are significant in females, which proves the positive relationship of perceived social support, subjective well-being, and resilience on psychological distress. These results are consistent with past literature (e.g., (Hasan \& Bao, 2020). Further, female university students are observed as a high propensity for resilience, perceived social support, and subjective well-being in our sample. On the other hand, the direct relationship between subjective well-being and resilience on psychological distress are proved significant in males. These results are consistent with past literature (Lin et al., 2020). Surprisingly, H1 is insignificant in males, which highlights that perceived social support has no positive relationship with psychological distress. These results are different from the past empirical studies (e.g., (Lin et al., 2020), that showed a positive impact.

Moreover, the second objective indicates the gender differences whereas the level of psychological distress is examined in males and female university students. The findings suggested that female university students have faced immense pressures and challenges of psychological distress, which can significantly affect their mental health, making it difficult for retention their university progress and even influence their academic performance. Moreover, university administration should enlighten their health care awareness regarding mental health knowledge which can facilitate student's mental health interventions and screen-out those students who are suffering from psychological distress. Interestingly, female students were reported as higher victims of psychological distress as comparing with male students, which is consistent with previous literature (Hao et al., 2020). These findings shed light on the importance of gender differences while dealing with the context of mental health 
in general, and psychological distress in particular. Psychological distress is a specific type of mental health problem that further corresponds to different problems and diseases of mental health, especially among university students. In the present study, gender differences may explain that females tend to perceive a higher prevalence of psychological distress than male students. Women are considered as higher intensity to fight against stress and anxiety, which is not stable as resiliencies and social support.

\section{Conclusion, Implications, and Limitations}

This study developed a model to explore the impacts of perceived social support, subjective well-being, and resilience on psychological distress. This study empirically supported the social support theory approach. Contrary to previous literature merely focusing on the gender difference in the relationship between perceived social support, subjective well-being, resilience, and psychological distress. This investigation confirmed gender difference as an emerging theme in this research. Since limited research is available in measuring gender difference context among university students in the field of educational psychology. This finding sheds additional light on identifying psychological factors in educational psychology literature.

The findings of this research have multiple implications. Although most of the past literature were conducted in developed countries, this study was carried out in a developing country (Pakistan); thus, providing a comprehensive overall view of gender differences within Pakistan public and private universities. This investigation is among the first gender difference studies endeavors in Pakistan. This study revealed that nearly more than half of the educational institutions are aware of psychological distress contexts, and they are implementing health care mechanisms as part of their curriculum and extra-curriculum activities. However, the results could not be specific just to Pakistan. Our analysis provided a starting point for additional research into psychological distress in emerging markets in Asia. In emerging nations, due to variation in education systems and higher education policies, psychological distress has different impacts between emerging and developed nations.

The study has contained several limitations. Firstly, the generalizability of these results is subjected to certain limitations. Present research selected educational institutions of Pakistan as the sample of the study, their practices, policies, programs, and regulations may not representatives of all over the universities in Pakistan. Moreover, as the sample is comprised of one province of Pakistan, it may have been generated different results in other provinces. Secondly, while psychological distress, as a psychological factor, include many dimensions and factors, this study only considered one psychological factor for assessing gender differences. By considering and measuring more components of psychological factors, the results could be more comprehensive and valuable. Finally, this study did not attempt to make a comparison between emerging and developed countries, hence, a comparative study could assist in properly analyze the actual issues regarding gender differences.

\section{References}

Anderson, A. R., Fowers, B. J. (2020). Lifestyle behaviors, psychological distress, and wellbeing: A daily diary study. Social Science \& Medicine, 263, 113263.

Ben-Tzur, N., Zanbar, L., \& Kaniasty, K. (2020). Mastery, social support, and sense of community as protective resources against psychological distress among Israelis exposed to prolonged rocket attacks. Journal of Traumatic Stress. 
Chen, J.K. (2020). Cyber victimisation, social support, and psychological distress among junior high school students in Taiwan and Mainland China. Asia Pacific Journal of Social Work and Development, 1-14.

Cohen, J. J. P. b. (1992). A power primer. Psychological bulletin, 112(1), 155.

Collie, A., Sheehan, L., Lane, T. J., \& Iles, R. (2020). Psychological Distress in Workers' Compensation Claimants: Prevalence, Predictors and Mental Health Service Use. Journal of occupational rehabilitation, 30(2), 194-202.

Every-Palmer, S., Jenkins, M., Gendall, P., Hoek, J., Beaglehole, B., Bell, C., . . . Stanley, J. (2020). Psychological distress, anxiety, family violence, suicidality, and wellbeing in New Zealand during the COVID-19 lockdown: A cross-sectional study. PloS one, 15(11), e0241658.

Glass, K., Flory, K., Hankin, B. L., Kloos, B., Turecki, G. J. (2009). Are coping strategies, social support, and hope associated with psychological distress among Hurricane Katrina survivors?. Journal of Social and Clinical Psychology, 28(6), 779-795.

Hair Jr, J. F., Sarstedt, M., Hopkins, L., \& Kuppelwieser, V. G. J. E. b. r. (2014). Partial least squares structural equation modeling (PLS-SEM). European business review.

Hamza, C. A., Ewing, L., Heath, N. L., \& Goldstein, A. L. (2020). When social isolation is nothing new: A longitudinal study psychological distress during COVID-19 among university students with and without preexisting mental health concerns. Canadian Psychology/Psychologie canadienne.

Hao, X., Zhou, D., Li, Z., Zeng, G., Hao, N., Li, E., . \& \& Yan, B. J. E. (2020). Severe psychological distress among patients with epilepsy during the COVID-19 outbreak in southwest China. Epilepsia.

Hartley, M. T. J. J. O. C. C. (2012). Assessing and promoting resilience: An additional tool to address the increasing number of college students with psychological problems. Journal of College Counseling, 15(1), 37-51.

Hasan, N., \& Bao, Y. J. C. (2020). Impact of "e-Learning crack-up" perception on psychological distress among college students during COVID-19 pandemic: A mediating role of "fear of academic year loss". Children and Youth Services Review, 118, 105355.

Henseler, J. J. Q. (2018). Partial least squares path modeling: Quo vadis?. Quality \& Quantity, 52(1), 1-8.

Holingue, C., Badillo-Goicoechea, E., Riehm, K. E., Veldhuis, C. B., Thrul, J., Johnson, R. M., . . \& Kalb, L. G. J. P. m. (2020). Mental distress during the COVID-19 pandemic among US adults without a pre-existing mental health condition: Findings from American trend panel survey. Preventive medicine, 139, 106231.

Kang, L., Ma, S., Chen, M., Yang, J., Wang, Y., Li, R., . . \& Hu, S. (2020). Impact on mental health and perceptions of psychological care among medical and nursing staff in Wuhan during the 2019 novel coronavirus disease outbreak: A cross-sectional study. Brain, behavior, and immunity.

Larsen, R. J., Diener, E., \& Emmons, R. A. (1985). An evaluation of subjective well-being measures. Social indicators research, 17(1), 1-17.

Latif, B., Mahmood, Z., Tze San, O., Mohd Said, R., \& Bakhsh, A. (2020). Coercive, Normative and Mimetic Pressures as Drivers of Environmental Management Accounting Adoption. Sustainability, 12(11), 4506.

Lin, C.-Y., Broström, A., Griffiths, M. D., \& Pakpour, A. H. (2020). Investigating mediated effects of fear of COVID-19 and COVID-19 misunderstanding in the association between 
problematic social media use, psychological distress, and insomnia. Internet interventions, 21, 100345.

Moore, K. A., \& Lucas, J. J. (2020). COVID-19 distress and worries: The role of attitudes, social support, and positive coping during social isolation. Psychology and Psychotherapy: Theory, Research and Practice.

Nishi, D., Imamura, K., Watanabe, K., Ishikawa, H., Tachimori, H., Takeshima, T., \& Kawakami, N. (2020). Psychological distress with and without a history of depression: Results from the World Mental Health Japan 2nd Survey (WMHJ2). Journal of Affective Disorders, 265, 545-551.

Petzold, M. B., Bendau, A., Plag, J., Pyrkosch, L., Mascarell Maricic, L., Betzler, F., . \& \& Ströhle, A. (2020). Risk, resilience, psychological distress, and anxiety at the beginning of the COVID-19 pandemic in Germany. Brain and behavior, 10(9), e01745.

Qiu, J., Shen, B., Zhao, M., Wang, Z., Xie, B., \& Xu, Y. (2020). A nationwide survey of psychological distress among Chinese people in the COVID-19 epidemic: implications and policy recommendations. General psychiatry, 33(2).

Richter, N. F., Cepeda-Carrión, G., Roldán Salgueiro, J. L., \& Ringle, C. M. (2016). European management research using partial least squares structural equation modeling (PLSSEM). European Management Journal, 34 , 589-597.

Ringle, C. M., \& Sarstedt, M. (2016). Gain more insight from your PLS-SEM results. Industrial Management \& Data Systems.

Satici, B., Gocet-Tekin, E., Deniz, M. E., \& Satici, S. A. (2020). Adaptation of the Fear of COVID19 Scale: Its association with psychological distress and life satisfaction in Turkey. International Journal of Mental Health and Addiction, 1.

Serafini, M. R. A., Powell, S. K., Frere, J. J., Saali, A., Krystal, H. L., Kumar, V., . \& \& Meah, M. Y. (2020). Psychological distress in the face of a pandemic: An observational study characterizing the impact of COVID-19 on immigrant outpatient mental health. Psychiatry research, 113595.

Shechter, A., Diaz, F., Moise, N., Anstey, D. E., Ye, S., Agarwal, S., . . \& Claassen, J. (2020). Psychological distress, coping behaviors, and preferences for support among New York healthcare workers during the COVID-19 pandemic. General hospital psychiatry, 66, 1-8.

Tsuchiya, M., Adachi, K., Kumagai, K., Kondo, N., \& Kimata, A. (2020). Cancer disclosure to friends: Survey on psychological distress and perceived social support provision. European Journal of Cancer Care, e13332.

Zhou, X. (2020). Managing psychological distress in children and adolescents following the COVID-19 epidemic: A cooperative approach. Psychological Trauma: Theory, Research, Practice, and Policy.

Zimet, G. D., Powell, S. S., Farley, G. K., Werkman, S., \& Berkoff, K. A. (1990). Psychometric characteristics of the multidimensional scale of perceived social support. Journal of personality assessment, 55(3-4), 610-617. 